\title{
Six Tips on How to Bring Epic Wins to Health Care
}

\author{
Anna Sort ${ }^{1,2}$ and Yasser Khazaal $\left.\right|^{3,4,5 *}$ \\ ${ }^{1}$ University of Barcelona, Barcelona, Spain, ${ }^{2}$ PlayBenefit, Barcelona, Spain, ${ }^{3}$ Research Centre of the Montreal University \\ Institute of Mental Health, Montreal, QC, Canada, ${ }^{4}$ University of Geneva, Geneva, Switzerland, ${ }^{5}$ Geneva University Hospitals, \\ Geneva, Switzerland
}

Keywords: games for health, gamification, Internet treatment, mental disorders, Internet

\section{INTRODUCTION}

Gamification and game-based treatment for mental health disorders are growing topics in the scientific literature. In health care, gamification is the use of various game processes in non-game contexts to engage users in behaviors that aim to improve health-related outcomes (1). In other words, gamification seeks to create motivational experiences that engage users in gameful actions and fulfill the human need for fun.

Several benefits are expected from the development of games for mental health, such as an increase in the reach of mental health interventions (appealing effect) and a reduction in the attrition rates of Internet-based interventions (engaging effect) $(2,3)$. Furthermore, games are expected to help behavioral change via situated learning (4) - which derives from achievements in participatory knowledge in immersive contexts-possibly involving activity, training, and social practice $(2,3,5-7)$. Over the past 5 years, a number of studies on board games and digital games have suggested that approaches such as the gamification of therapeutic processes or casual games used for therapeutic purposes have the potential to promote cognitive and behavioral change and improvements in symptoms (8-21). A well-designed recent meta-analysis (22) that included nine randomized controlled trials (i.e., 674 participants) assessed the effectiveness of digital serious games (SGs) for the symptoms of mental disorder. The authors found a moderate effect on the improvement of symptoms that favored SGs over controls. They concluded that SGs may be effective in reducing the symptoms of mental disorder and asked for additional studies in this promising field.

The assessed games varied widely in their aims (e.g., psychoeducation, cognition training, goal-oriented, problem solving), format (e.g., involving avatars, fantasy world, personalization, exergames) and mechanisms. Some of these games were designed for treatment, while others were casual games (e.g., "Tetris") used in expectation of a therapeutic effect (22). Unsurprisingly, therapeutically designed games vary widely in their theoretical background depending on their specific aims. For example, the game called "Let's Face It!" is based on the theory of enhancement of recognition skills and aims to increase facial recognition abilities (23), the game called "Sparx" is based on cognitive behavioral therapy (CBT) and seeks to treat depressive symptoms (10), and "Michael's Game," which is based on the principles of CBT for psychotic disorders, aims to reduce delusional conviction (8).

Some reviews have reported, however, that most health-related games lack several typical immersive gamification features (24) and have a limited theoretical foundation (25). In addition, despite promising results and the a priori engaging nature of games, high rates of attrition and a decrease in game use over time have been previously reported $(26,27)$. For instance, none of the 1,622 adolescents participating in a study on a computerized game designed for reducing binge drinking completed the five sessions of the game (28). Thus, although game design provides flexible opportunities to promote behavior change, target goals need to be reached in order for games to be successfully adopted by users. 
Despite the attractiveness (29) and potential of games, the processes underlying game design have not been reported in detail in most game-related studies. This weakness has commonly been reported in the literature for behavior change interventions (30) and has led to a lack of guidance on how to practically design such interventions, particularly in health-related games (31).

The present opinion paper aims to outline possible steps to follow in order to implement gamification in health care by using adequate solutions. SGs must demonstrate the transfer of learning (to be "serious") while, at the same time, remaining engaging and entertaining (to be "games"). The balance between fun and educational measures should be targeted throughout game development, starting from the design phase. Yet, despite the potential of digital games in terms of interactivity, immersion, and engagement, further studies are needed to understand how to better design, administer, and assess such games across different learning contexts and targets $(31,32)$. To date, the insufficient integration of behavior change and game design principles is one of the biggest issues with SGs (27).

The proposed tips for gamification are as follows.

\section{KNOW WHAT YOUR GOALS ARE}

Translating goals into game design mechanisms and processes is the pinnacle of gamification (31). In other words, one of the most important steps to ensure a successful outcome of the engagement design is to know what your goals are (i.e., the game goals and the real-life outcome goals). Accordingly, users' engagement is expected to increase when their expectations match the goal of the intervention (5). To move from general, non-specific goals to more specific goals and to refine goal setting (33), it might be useful to involve designers, clinicians, and end users in collaborative workshops.

\section{PUT THE USER FIRST}

As obvious as it may sound, this second tip is too frequently disregarded. Giving priority to the client's or the patient's experience is a necessary condition for meeting end users' needs effectively (3). Designers often do a great job in thinking about how to get the best results, but then completely forget to consider how to interest older adults in using a tablet and a medical device, how to teach them to use the device, and how to warn them that they even have to use a device. Therefore, the project might be doomed to failure before it even begins. By putting the users' experience first, you will understand exactly what you want the users to go through, as well as what they are going through. As a result, you will ensure that game processes are designed to suit the users' needs and abilities.

This is a crucial step in developing, planning, and performing actions that succeed in promoting goal attainment in the game (33). It involves considering the main determinants of the given behavior, possible short- and long-term concurrent goals, practical obstacles, and the correspondence between the goal and the users' self-image, self-compassion, and values (34-37). When you meet with users, adopting a detailed approach may help you precisely describe the steps they take and their level of stress with each step. It is important to ask them to describe the steps that they expect next for their benefit, as well as any "crazy ideas" they may have. In the end, you might gain valuable insights into what users are doing, what they would like to happen and what they would love to happen.

Furthermore, game designs must be tailored to the needs and capabilities of the target group in order to enhance motivation and fun (38), self-efficacy (39), and adherence (38). For instance, recently published design recommendations for older adults' SGs have taken age-related cognitive change into account (40). Giving priority to the user's experience could be achieved by using participatory, user-centered design, i.e., continuously involving users at every stage of development or formative research steps and collecting information from the target group to ensure that game processes are in tune with their needs and capabilities (41). Despite its theoretical importance, the impact of participatory design (PD) on game engagement and effectiveness is nevertheless inconclusive and is likely to depend on the type of PD and focus. Nonetheless, involving users in the development of key game components may be more effective than involving them in esthetic appreciation $(41,42)$.

\section{USE BEHAVIOR CHANGE THEORIES TO INSPIRE YOUR GAMIFICATION}

When thinking about "gamifying" something, bear in mind what behavior you want to change. Do you want people to be using something they are not using now? Do you want them to increase the number of times a day they use something-something they currently use only once a day? Do you want to introduce something new into their routine? Are the people you want to help facing specific competing impulses or inhibitions related to the game's main pursued goal? Are knowledge, specific beliefs, expectations, or barriers influencing the given behavior? Is the game addressing motivation, self-regulatory capacity, or any other specific skill? These are concerns that must be addressed to define what should be achieved in terms of behavior and to reach your goal. To do so adequately, using a given behavior change theory $(30,43)$ provides helpful guidance in the game design process (44).

Considering the variety of behavior change theories and their differences in focus and construct-such as the Health Belief Model, the Theory of Planned Behavior, and self-control and willpower-related models $(43,45,46)$-it is important to choose the most appropriate guidance in line with the game's goals.

Some studies found that explicit reliance on behavior change theory and its related techniques $(47,48)$ was associated with better outcomes $(49,50)$. Unfortunately, most of the available health-related digital interventions did not explicitly rely on such theory (51-55). Moreover, specific behavior change techniques may vary across goals and topics $(47,48,56,57)$. However, some behavior change theories such as the Self-determination Theory (58), Fogg's Behavior Model (59), and Social Cognitive Theory (SCT) (60) may provide guidance about game development across health-care sectors.

Self-determination Theory (58) highlights the importance of competence (the need to control the outcome, to experience 
mastery), relatedness (being connected with others), and autonomy in the change process, as well as of a coherent framework in game design (5). Fogg's Behavior Model states that behavior change is a function of three fundamental elements: motivation, ability, and trigger (e.g., a motivating element, a facilitator, a signal) (59). SCT (60) focuses on how to change self-efficacy-a main determinant of behavior change-when facing barriers in achieving goals and suggests different solutions such as vicarious experiences. A smoking cessation game, leading to an increase in self-efficacy based on game processes and learning situations related to the barriers usually faced by people trying to change their smoking behavior, provides a valuable illustration of that process (11).

To improve the articulation between the different components of game design for behavior change, Starks proposed a cognitive behavioral game design framework (44). This framework involves the SCT, the Theory of Multiple Intelligences (MI), and gamification processes (44). MI tackles the multiple ways of achieving learning and experiences (music, mathematics, logic, humor, narratives) and highlights the game's ability to use a multimodal approach, possibly combining sensoriality, emotions, and rational thinking (61). The author (44) summarized the challenge of game design in the question, "How do I express one or more social cognitive elements through the mechanism of one or more intelligences in a way that facilitates the enjoyment process?" thereby referring to the involvement of game theories in the design of SGs.

\section{USE PLAY, FUN, AND GAMES THEORIES}

It makes little sense to talk about gamification and then create something utterly boring. But how exactly does one create fun? The following three features are particularly helpful in developing a game process:

- The type of player: what is the target group more likely to engage in?

- Flow theory: full immersion and energized focus

- The player's journey

The player's journey is essential to gamification for structuring vision, content, and progression. Have you ever been on a website where you were overloaded with choice and yet had no idea how to find what you were looking for? Conversely, have you ever been on a website with little choice and without a search function, which did not help you to find what you were looking for? These examples both address the issues of purpose, autonomy, and mastery. Accordingly, if people have greater autonomy, but have no idea where they are heading-in other words, if they have little mastery-they find themselves in the first example. If they have a high level of mastery but little autonomy, they find themselves in the second example. The purpose in finding something needed on a web page is essential for a satisfying experience. Indeed, without purpose, there is no action (62).

When setting up and developing a solution, consideration of the gamer's journey will help structure what you want users to find first. This will help you understand the basic features of the system that users might need to proceed to the next level, so that they do not feel over-challenged, but confident enough in their ability to take up the next challenge with mastery. These three features are closely related to one another for distinguishing what is boring from what is engaging: too much mastery with little autonomy is as boring as too much autonomy and a low level of mastery of what one is doing or supposed to do or achieve (6). According to Flow Theory and Motivation (63), activities that provide an optimal balance between challenge level and skill acquisition level create a motivational state of flow. The flow enhances immersion, creativity, and performance.

Building an attractive journey for the player with optimal flow further requires a sound knowledge of the audience's perceived health-related needs, as well as of possible gamer types-e.g., an achiever is motivated by mastery, a socializer by social interactions, a philanthropist by purpose, and a free spirit by autonomy $(64,65)$

\section{BE MINDFUL OF THE SOCIAL LINK}

According to Self-determination Theory (66), relatedness (e.g., the social link) is one of the keystones in behavior change processes. Many studies have shown the benefit of having a buddy, a community, or some kind of social support when one engages in a process, be it about improving wellness and fitness or dealing with a disease (39).

In games, it is easy to understand how these varied social interactions develop in a fun way. Amy Jo Kim-a game designer known for her career and work on games such as "The Sims"- -has developed a social interaction chart (67) that shows the different ways in which people engage socially, some of which might seem more meaningful than others, depending on the type of player.

Social interactions may bring meaning into the system that you are implementing and may encourage bonding and a sense of belonging, which can be powerful for driving behavior change. In the game design process, social interactions can be divided into three categories corresponding to the following questions:

- Who are players sharing the experience with? A community? A chosen buddy? Their family?

- What feelings do you want players to derive from social links? Recognition? A sense of belonging to something bigger than themselves? Feedback? Naches (i.e., pride in the achievement of offspring or an apprentice, the joy that can be felt without doing anything directly)?

- Keeping the pursued goal in mind, what type of interactions are you looking for? As everyone likes to engage in interactions in different ways - although they might prefer one at a given time-they usually choose from several "interaction types."

\section{IT IS NOT JUST ABOUT GAME MECHANICS AND GAME DYNAMICS}

Gamification is about games and about making games appealing. Indeed, it is critical to keep in mind that the system has to be attractive enough for gamers to continue using it, even if points, 
badges and leader boards are removed (1). One should favor mechanics such as meaningful feedback and timely rewards that help gamers to improve their standing or to proceed to the next level more effectively (68). This will ensure that, besides appealing to users who favor extrinsic motivators (e.g., a Smart Box, tablets, etc.), your system will appeal to those who favor intrinsic motivators (e.g., learning) $(69,70)$ and may secure users' engagement in the game for a longer time.

When designing games, one should also keep in mind that static things, although exciting at first, can easily lose their appeal. By way of illustration, the Fun Theory piano stair (71) is a cool way of making people choose regular stairs rather than the escalator; but would people feel the same way after 5 days? 10 days? Providing a game experience that is difficult enough for users to feel challenged (where they must make an effort to succeed), but easy enough for them to remain confident that they can succeed, may be the condition for keeping users engaged in the game. Conversely, providing a game experience where users repeat the same actions over and over may cause them to lose interest.

\section{REFERENCES}

1. Cugelman B. Gamification: what it is and why it matters to digital health behavior change developers. JMIR Serious Games (2013) 1(1):e3. doi:10.2196/ games.3139

2. Fleming TM, Bavin L, Stasiak K, Hermansson-Webb E, Merry SN, Cheek C, et al. Serious games and gamification for mental health: current status and promising directions. Front Psychiatry (2016) 7:215. doi:10.3389/fpsyt.2016.00215

3. Fleming TM, de Beurs D, Khazaal Y, Gaggioli A, Riva G, Botella C, et al. Maximizing the impact of e-therapy and serious gaming: time for a paradigm shift. Front Psychiatry (2016) 7:65. doi:10.3389/fpsyt.2016.00065

4. Lave J, Wenger E. Situated Learning: Legitimate Peripheral Participation. Cambridge: Cambridge University Press (1991).

5. Cheek C, Fleming T, Lucassen MF, Bridgman H, Stasiak K, Shepherd M, et al. Integrating health behavior theory and design elements in serious games. JMIR Ment Health (2015) 2(2):e11. doi:10.2196/mental.4133

6. Csikszentmihalyi M. Flow, the Secret to Happiness: Ted.com. (2004). Available from: https://www.ted.com/talks/mihaly_csikszentmihalyi_on_ flow?language $=$ en

7. Khazaal Y, Favrod J, Azoulay S, Finot SC, Bernabotto M, Raffard S, et al. "Michael's game," a card game for the treatment of psychotic symptoms. Patient Educ Couns (2011) 83(2):210-6. doi:10.1016/j.pec.2010.05.017

8. Khazaal Y, Chatton A, Dieben K, Huguelet P, Boucherie M, Monney G, et al. Reducing delusional conviction through a cognitive-based group training game: a multicentre randomized controlled trial. Front Psychiatry (2015) 6:66. doi:10.3389/fpsyt.2015.00066

9. Fleming T, Dixon R, Frampton C, Merry S. A pragmatic randomized controlled trial of computerized CBT (SPARX) for symptoms of depression among adolescents excluded from mainstream education. Behav Cogn Psychother (2012) 40(5):529-41. doi:10.1017/S1352465811000695

10. Merry SN, Stasiak K, Shepherd M, Frampton C, Fleming T, Lucassen MF. The effectiveness of SPARX, a computerised self help intervention for adolescents seeking help for depression: randomised controlled non-inferiority trial. $B M J$ (2012) 344:e2598. doi:10.1136/bmj.e2598

11. Khazaal Y, Chatton A, Prezzemolo R, Zebouni F, Edel Y, Jacquet J, et al. Impact of a board-game approach on current smokers: a randomized controlled trial. Subst Abuse Treat Prev Policy (2013) 8:3. doi:10.1186/1747-597X-8-3

12. Cutter CJ, Schottenfeld RS, Moore BA, Ball SA, Beitel M, Savant JD, et al. A pilot trial of a videogame-based exercise program for methadone maintained patients. J Subst Abuse Treat (2014) 47(4):299-305. doi:10.1016/j. jsat.2014.05.007

\section{FURTHER STEPS}

Because further improvements in health-related games are needed, we encourage further studies to be done to explicitly describe the game design process, possibly by using the six tips described in the present paper. This may help to further refine game design taxonomy in the field. Assessing health-related outcomes that have already been achieved in a number of studies, as well as linking such outcomes to intra-game processes and gamers' profiles, might also prove valuable.

\section{AUTHOR CONTRIBUTIONS}

We confirm that all authors contributed equally to the writing of this manuscript.

\section{ACKNOWLEDGMENTS}

We thank Barbara Every, ELS, of BioMedical Editor, for English language editing.

13. Peng W, Pfeiffer KA, Winn B, Lin JH, Suton D. A pilot randomized, controlled trial of an active video game physical activity intervention. Health Psychol (2015) 34(Suppl):1229-39. doi:10.1037/hea0000302

14. Leutwyler H, Hubbard E, Cooper B, Dowling G. The impact of a videogamebased pilot physical activity program in older adults with schizophrenia on subjectively and objectively measured physical activity. Front Psychiatry (2015) 6:180. doi:10.3389/fpsyt.2015.00180

15. Strahler Rivero T, Herrera Nunez LM, Uehara Pires E, Amodeo Bueno OF. ADHD rehabilitation through video gaming: a systematic review using PRISMA guidelines of the current findings and the associated risk of bias. Front Psychiatry (2015) 6:151. doi:10.3389/fpsyt.2015.00151

16. Tarrega S, Castro-Carreras L, Fernandez-Aranda F, Granero R, GinerBartolome C, Aymami N, et al. A serious videogame as an additional therapy tool for training emotional regulation and impulsivity control in severe gambling disorder. Front Psychol (2015) 6:1721. doi:10.3389/fpsyg.2015.01721

17. Amado I, Brenugat-Herne L, Orriols E, Desombre C, Dos Santos M, Prost Z, et al. A serious game to improve cognitive functions in schizophrenia: a pilot study. Front Psychiatry (2016) 7:64. doi:10.3389/fpsyt.2016.00064

18. Bul KC, Kato PM, Van der Oord S, Danckaerts M, Vreeke LJ, Willems A, et al. Behavioral outcome effects of serious gaming as an adjunct to treatment for children with attention-deficit/hyperactivity disorder: a randomized controlled trial. J Med Internet Res (2016) 18(2):e26. doi:10.2196/jmir.5173

19. Fish MT, Russoniello CV, O’Brien K. The efficacy of prescribed casual videogame play in reducing symptoms of anxiety: a randomized controlled study. Games Health J (2014) 3(5):291-5. doi:10.1089/g4h.2013.0092

20. Davies C, Malik A, Pictet A, Blackwell SE, Holmes EA. Involuntary memories after a positive film are dampened by a visuospatial task: unhelpful in depression but helpful in mania? Clin Psychol Psychother (2012) 19(4):341-51. doi:10.1002/cpp. 1800

21. Li J, Theng YL, Foo S. Game-based digital interventions for depression therapy: a systematic review and meta-analysis. Cyberpsychol Behav Soc Netw (2014) 17(8):519-27. doi:10.1089/cyber.2013.0481

22. Lau HM, Smit JH, Fleming TM, Riper H. Serious games for mental health: are they accessible, feasible, and effective? A systematic review and meta-analysis. Front Psychiatry (2016) 7:209. doi:10.3389/fpsyt.2016.00209

23. Tanaka JW, Wolf JM, Klaiman C, Koenig K, Cockburn J, Herlihy L, et al. Using computerized games to teach face recognition skills to children with autism spectrum disorder: the Let's Face It! program. J Child Psychol Psychiatry (2010) 51(8):944-52. doi:10.1111/j.1469-7610.2010.02258.x

24. DeSmet A, Shegog R, Van Ryckeghem D, Crombez G, De Bourdeaudhuij I. A systematic review and meta-analysis of interventions for sexual health 
promotion involving serious digital games. Games Health J(2015) 4(2):78-90. doi:10.1089/g4h.2014.0110

25. Tabak M, Dekker-van Weering M, van Dijk H, Vollenbroek-Hutten M. Promoting daily physical activity by means of mobile gaming: a review of the state of the art. Games Health J (2015) 4(6):460-9. doi:10.1089/g4h. 2015.0010

26. Maloney AE, Mellecker R, Buday R, Gao Z, Hinkley T, Esparza L, et al. Fun, flow, and fitness: opinions for making more effective active videogames. Games Health J (2015) 4(1):53-7. doi:10.1089/g4h.2014.0081

27. Sardi L, Idri A, Fernandez-Aleman JL. A systematic review of gamification in e-Health. J Biomed Inform (2017) 71:31-48. doi:10.1016/j.jbi.2017.05.011

28. Jander A, Crutzen R, Mercken L, Candel M, de Vries H. Effects of a web-based computer-tailored game to reduce binge drinking among dutch adolescents: a cluster randomized controlled trial. J Med Internet Res (2016) 18(2):e29. doi:10.2196/jmir.4708

29. Thorens G, Billieux J, Megevand P, Zullino D, Rothen S, Achab S, et al. Capitalizing upon the attractive and addictive properties of massively multiplayer online role-playing games to promote wellbeing. Front Psychiatry (2016) 7:167. doi:10.3389/fpsyt.2016.00167

30. Michie S, Johnston M, Francis J, Hardeman W, Eccles M. From theory to intervention: mapping theoretically derived behavioural determinants to behaviour change techniques. Appl Psychol (2008) 57(4):660-80. doi:10.1111/j.1464-0597.2008.00341.x

31. Arnab S, Lim T, Carvalho MB, Bellotti F, Freitas S, Louchart S, et al. Mapping learning and game mechanics for serious games analysis. Br JEduc Technol (2015) 46(2):391-411. doi:10.1111/bjet.12113

32. de Freitas S, Liarokapis F. Serious games: a new paradigm for education? In: Springer NM, editor. Serious Games and Edutainment Applications. London: Springer (2011). p. 9-23.

33. Mann T, de Ridder D, Fujita K. Self-regulation of health behavior: social psychological approaches to goal setting and goal striving. Health Psychol (2013) 32(5):487-98. doi:10.1037/a0028533

34. Oyserman D, Smith GC, Elmore K. Identity based motivation: implications for health and health disparities. J Soc Issues (2014) 70(2):206-25. doi:10.1111/ josi. 12056

35. MacBeth A, Gumley A. Exploring compassion: a meta-analysis of the association between self-compassion and psychopathology. Clin Psychol Rev (2012) 32(6):545-52. doi:10.1016/j.cpr.2012.06.003

36. Cohen GL, Sherman DK. The psychology of change: self-affirmation and social psychological intervention. Annu Rev Psychol (2014) 65:333-71. doi:10.1146/ annurev-psych-010213-115137

37. Ajzen I, Brown TC, Carvajal F. Explaining the discrepancy between intentions and actions: the case of hypothetical bias in contingent valuation. Pers Soc Psychol Bull (2004) 30(9):1108-21. doi:10.1177/0146167204264079

38. Bleakley CM, Charles D, Porter-Armstrong A, McNeill MD, McDonough SM, McCormack B. Gaming for health: a systematic review of the physical and cognitive effects of interactive computer games in older adults. J Appl Gerontol (2015) 34(3):N166-89. doi:10.1177/0733464812470747

39. Perski O, Blandford A, West R, Michie S. Conceptualising engagement with digital behaviour change interventions: a systematic review using principles from critical interpretive synthesis. Transl Behav Med (2017) 7(2):254-67. doi:10.1007/s13142-016-0453-1

40. Salmon JP, Dolan SM, Drake RS, Wilson GC, Klein RM, Eskes GA. A survey of video game preferences in adults: building better games for older adults. Entertain Comput (2017) 21:45-64. doi:10.1016/j.entcom.2017.04.006

41. DeSmet A, Thompson D, Baranowski T, Palmeira A, Verloigne M, De Bourdeaudhuij I. Is participatory design associated with the effectiveness of serious digital games for healthy lifestyle promotion? A meta-analysis. J Med Internet Res (2016) 18(4):e94. doi:10.2196/jmir.4444

42. Thompson D. Incorporating behavioral techniques into a serious videogame for children. Games Health $J$ (2017) 6(2):75-86. doi:10.1089/g4h. 2016.0066

43. Webb TL, Sniehotta FF, Michie S. Using theories of behaviour change to inform interventions for addictive behaviours. Addiction (2010) 105(11):1879-92. doi:10.1111/j.1360-0443.2010.03028.x

44. Starks K. Cognitive behavioral game design: a unified model for designing serious games. Front Psychol (2014) 5:28. doi:10.3389/fpsyg.2014.00028

45. McGonigal K. The Willpower Instinct: How Self-Control Works, Why It Matters, and What You Can Do to Get More of It. London: Penguin (2011).
46. Noel X, Bechara A, Brevers D, Verbanck P, Campanella S. Alcoholism and the loss of willpower: a neurocognitive perspective. J Psychophysiol (2010) 24(4):240-8. doi:10.1027/0269-8803/a000037

47. Abraham C, Michie S. A taxonomy of behavior change techniques used in interventions. Health Psychol (2008) 27(3):379-87. doi:10.1037/0278

48. Michie S, Hyder N, Walia A, West R. Development of a taxonomy of behaviour change techniques used in individual behavioural support for smoking cessation. Addict Behav (2011) 36(4):315-9. doi:10.1016/j.addbeh.2010.11.016

49. West R, Walia A, Hyder N, Shahab L, Michie S. Behavior change techniques used by the English Stop Smoking Services and their associations with shortterm quit outcomes. Nicotine Tob Res (2010) 12(7):742-7. doi:10.1093/ntr/ ntq074

50. Webb TL, Joseph J, Yardley L, Michie S. Using the internet to promote health behavior change: a systematic review and meta-analysis of the impact of theoretical basis, use of behavior change techniques, and mode of delivery on efficacy. J Med Internet Res (2010) 12(1):e4. doi:10.2196/jmir.1376

51. Azar KM, Lesser LI, Laing BY, Stephens J, Aurora MS, Burke LE, et al. Mobile applications for weight management: theory-based content analysis. Am J Prev Med (2013) 45(5):583-9. doi:10.1016/j.amepre.2013.07.005

52. Choi J, Noh GY, Park DJ. Smoking cessation apps for smartphones: content analysis with the self-determination theory. J Med Internet Res (2014) 16(2):e44. doi:10.2196/jmir.3061

53. Crane D, Garnett C, Brown J, West R, Michie S. Behavior change techniques in popular alcohol reduction apps: content analysis. J Med Internet Res (2015) 17(5):e118. doi:10.2196/jmir.4060

54. Penzenstadler L, Chatton A, Van Singer M, Khazaal Y. Quality of smartphone apps related to alcohol use disorder. Eur Addict Res (2016) 22(6):329-38. doi:10.1159/000449097

55. Van-Singer M, Chatton A, Khazaal Y. Quality of smartphone apps related to panic disorder. Front Psychiatry (2015) 6:96. doi:10.3389/fpsyt.2015.00096

56. Michie S, Ashford S, Sniehotta FF, Dombrowski SU, Bishop A, French DP. A refined taxonomy of behaviour change techniques to help people change their physical activity and healthy eating behaviours: the CALO-RE taxonomy. Psychol Health (2011) 26(11):1479-98. doi:10.1080/08870446.2010.540664

57. Michie S, Richardson M, Johnston M, Abraham C, Francis J, Hardeman W, et al. The behavior change technique taxonomy (v1) of 93 hierarchically clustered techniques: building an international consensus for the reporting of behavior change interventions. Ann Behav Med (2013) 46(1):81-95. doi:10.1007/s12160-013-9486-6

58. Deci EL, Ryan RM. Self-determination theory in health care and its relations to motivational interviewing: a few comments. Int J Behav Nutr Phys Act (2012) 9:24. doi:10.1186/1479-5868-9-24

59. Dichev C, Dicheva D, Angelova G, Agre G. From gamification to gameful design and gameful experience in learning. Cybern Inform Technol (2014) 14(4):80-100. doi:10.1515/cait-2014-0007

60. Bandura A. Social cognitive theory: an agentic perspective. Annu Rev Psychol (2001) 52:1-26. doi:10.1146/annurev.psych.52.1.1

61. Desseilles M. Perspectives on games, computers, and mental health: questions about paradoxes, evidences, and challenges. Front Psychiatry (2016) 7:122. doi:10.3389/fpsyt.2016.00122

62. PInk D. Autonomy, Mastery and Purpose. (2012).

63. Hamari J, Shernoff DJ, Rowe E, Coller B, Asbell-Clarke J, Edwards T. Challenging games help students learn: An empirical study on engagement, flow and immersion in game-based learning. Comput Human Behav (2016) 54:170-9. doi:10.1016/j.chb.2015.07.045

64. Kim B. Designing gamification in the right way. Libr Technol Rep (2015) 51(2):29-35.

65. Tondello GF, Wehbe RR, Diamond L, Busch M, Marczewski A, Nacke LE. The gamification user types Hexad scale. Annual Symposium on Computer-Human Interaction in Play. Austin, Texas (2016). p. 229-43.

66. Ryan RM, Deci EL. Self-determination theory and the facilitation of intrinsic motivation, social development, and well-being. Am Psychol (2000) 55(1):68-78. doi:10.1037/0003-066X.55.1.68

67. Amy-Jo K. Beyond Player Types: Kim's Social Action Matrix. (2014).

68. Manriquey V. Epic Win Blog. (2013). Available from: http://www.epicwinblog. net/2013/10/the-35-gamification-mechanics-toolkit.html

69. Ryan RM, Deci EL. Intrinsic and extrinsic motivations: classic definitions and new directions. Contemp Educ Psychol (2000) 25(1):54-67. doi:10.1006/ ceps. 1999.1020 
70. Wu M. Science of Social Blog. (2016). Available from: https://community. lithium.com/t5/Science-of-Social-blog/Intrinsic-vs-Extrinsic-Rewards-andTheir-Differences-from/ba-p/128969

71. The-Wong-Janice. Piano Stairs Song. (2010). Available from: https://www. youtube.com $/$ watch?v=2lXh2n0aPyw

Conflict of Interest Statement: AS is CEO of PlayBenefit and YK is one of the authors of the following games: "Michael's Game" and "Pick-Klop."
The reviewer MP and handling editor declared their shared affiliation.

Copyright (C) 2017 Sort and Khazaal. This is an open-access article distributed under the terms of the Creative Commons Attribution License (CC BY). The use, distribution or reproduction in other forums is permitted, provided the original author(s) or licensor are credited and that the original publication in this journal is cited, in accordance with accepted academic practice. No use, distribution or reproduction is permitted which does not comply with these terms. 